\title{
Chinese Doctoral Students' Perceptions of Their University Instructors in the United States
}

\author{
Lulu Dong ${ }^{1, *} \&$ Mary M. Chittooran ${ }^{1}$ \\ ${ }^{1}$ Saint Louis University, St. Louis, USA \\ *Corresponding author: Saint Louis University, 3694 West Pine Mall, St. Louis, MO 63108 \\ USA
}

Received: November 6, 2012 Accepted: December 4, 2012 Published: December 25, 2012

doi:10.5296/ije.v4i4.2633 URL: http://dx.doi.org/10.5296/ije.v4i4.2633

\begin{abstract}
This study examines Chinese doctoral students' perceptions regarding their U.S. university instructors' academic and interactive behaviors. The author interviewed ten Chinese doctoral students from two universities in the Midwest. Participants discussed their instructors' academic behaviors, including pedagogical knowledge, instruction, and engagement, and their interactive behaviors, including openness, availability, and respect for students. Participants compared instruction and teaching between U.S. universities and universities in China. In general, all ten participants were quite satisfied with instructors in U.S. universities. This study addresses implications for research, Chinese students and their U.S. instructors, and university administrators.
\end{abstract}

Keywords: Chinese doctoral student; university instructor; academic behavior; interactive behavior 


\section{Introduction}

There has been a significant increase during the past two decades in the number of international students entering the U.S. to pursue higher education. The Institute of International Education, which has conducted an annual statistical survey of international students in the United States since 1949, released its most recent report on November 12, 2012 (Open Doors, 2012). This report suggested that the number of international students at colleges and universities in the United States increased by six percent to 764,495 during the 2011-12 academic year and that they contributed more than $\$ 22.7$ billion to the U.S. economy through their tuition and living expenses.

According to Kelly and Moogan (2012), increases in global mobility and the subsequent increase in the diversity of learners with regard to cultural background, language, age, and experience, present challenges to students, educators, and higher education institutions. Ku et al. (2004) state that many professors in the U.S. know little about international students. They do not have in-depth knowledge about the countries from which their students come. Because of cultural and background differences between the U.S. and other foreign countries, and because international students differ with regard to their perceptions and needs, it is increasingly important for U.S. faculty to fully understand the specific needs and demands of these students. The Open Doors report (2012) indicates that the growth of international student enrollments is greatly driven by significant increases in the number of students from China, particularly at the undergraduate level. Chinese student enrollments at U.S. universities have increased by 23 percent in total and by 31 percent at the undergraduate level. Because of the large number of Chinese students who have been admitted to U.S. universities, it is important to study their experiences and their perspectives in more detail. It is only when we have this information, that we can determine how to provide for their needs most effectively.

Chinese students studying at U.S. universities represent a critical part of the international student population in the U.S. Chinese students are from a country that has a different culture, language, and political and educational system than those in the U.S. Trained in Chinese education concepts for almost 20 years, Chinese doctoral students come to graduate schools in the U.S. to acquire knowledge and advanced information. They are exposed to a completely different educational and social environment and have to get accustomed to unfamiliar instructional practices in the U.S. as well as an unfamiliar lifestyle. Instructors in the U.S. will greatly influence Chinese doctoral students who depend on them to facilitate their adjustment to life in the U.S. This study explores mainland Chinese doctoral students' perceptions of their university instructors in the U.S.

\section{Purpose}

The purpose of this study was to explore mainland Chinese doctoral students' perceptions of their university instructors in the U.S., particularly with regard to their characteristics and behaviors. This study answered the following main research question: 
What are Chinese doctoral students' perceptions of their university instructors in the U.S.? and two sub-questions: a) What are Chinese doctoral students' perceptions of their university instructors' academic behaviors? and b) What are Chinese doctoral students' perceptions of their university instructors' interactive behaviors? Academic behaviors of instructors refer broadly to behaviors related to content knowledge and instruction that facilitate instructional performance while interactive behaviors of instructors refer generally to instructors' non-academic, interpersonal behaviors that facilitate the building of relationships with students.

A search of the literature shows that several researchers, including Feldman (1976), Ediger (1998), Nilson (1998), Hall (2002), Grasha (2004), and Austin (2005) have identified a variety of quality indicators related to positive instructor behaviors. These quality indicators, which were investigated in the current study, include pedagogical knowledge, instruction, engagement, openness, availability, and respect for students. Pedagogical knowledge, instruction, and engagement represent academic behaviors of instructors while openness, availability, and respect for students relate to interactive behaviors of instructors.

\section{Literature Review}

\subsection{University instructors and instruction in the United States}

Instructional excellence in higher education has been the topic of recent discussion in the literature. Baiocco and DeWaters (1998) believed, "excellent instructors are the embodiment of the interface of natural abilities (innate character tendencies) and nurture (learned aspects of personality and acquired knowledge) as evidenced in teaching behaviors" (p. 99). They discovered that character was the criterion for evaluation, promotion and tenure in higher education in the United States.

Other scholars have discussed a number of approaches to promote instructional excellence in higher education settings. For example, Dantas (2007) discussed instructors' competency to work with diverse learners in the context of international education. She stated that increasing diversity and complexity in classrooms are in evidence in educational institutions all over the world. This is particularly true in the U.S., which faces the challenge of dealing with the needs of a growing and diverse student population. Working with such a population requires an increasing focus on cultural competence, teacher preparation, instructional effectiveness, and professional development. The realities for instructors are even more challenging, because they face increasing pressure due to high-stakes testing and restrictive content standards.

Bain (2004), in his book, What the Best College Instructors Do, aimed at finding the best instructors across the U.S. at the college and university level. Bain emphasized the fact that exceptional instruction came from a coherent set of attitudes and assumptions about how students learned. All instructors in Bain's book were student-centered instead of disciplineor instructor-centered, though disciplinary mastery was a necessity for exceptional instruction. The best instructors in Bain's book realized where students were likely to encounter 
difficulties, were able to predict misunderstandings that students might have in a field of study, and then used the misunderstanding as a starting point for their courses. The best instructors aroused the interest of their students by providing them with real issues and questions, asked their students to engage in work that was similar to the work of the best practitioners in a field, and did this in a non-threatening and supportive atmosphere. In addition, these instructors were more willing to listen to their students and so were better able to motivate them.

Not all students are alike. Based on this knowledge, Hall (2002) explained differentiated instruction as follows: "differentiated instruction applies an approach to instruction and learning so that students have multiple options for taking in information and making sense of ideas" (p. 1). This model of differentiated instruction required instructors to be flexible in their approach to instruction and to adjust the curriculum and presentation of information for learners rather than expect students to modify themselves for the curriculum. Classroom instruction is an integration of whole-class, group and individual instruction and differentiated instruction is based on the premise that instructional approaches should vary and be adapted according to individual and diverse students in the classroom. Instructors should recognize differences in students' background knowledge, readiness, language, preferences in learning style, and interests, and should use that information to vary instruction to meet the needs of students. The purpose of differentiating instruction is to maximize each student's growth and individual success by meeting each student's needs in the learning process (Hall, 2002).

Burbank et al. (2005) raised a critical problem faced by educators today, namely, the inability of the education system to produce adequate numbers of instructors from racial, ethnic, and language minority groups. Increased numbers of culturally diverse instructors would be beneficial to students and society and educators and experts in multicultural education need to work together to increase the number of culturally diverse instructors in the schools. Educators who support increasing the presence of culturally diverse individuals in education propose that instructors from minority groups should be recruited to serve as role models for students from minority groups, provide culturally relevant instruction by helping to bridge differences between students' cultures and their schools, and offer diverse perspectives on appropriate and effective practices for all students.

\subsection{Academic and social adjustment of international students}

The number of international students studying in U.S. colleges and universities has continued to increase. Lee (2007) tested whether linguistic and/or cultural factors were related to East Asian students' level of oral participation in U.S. university classrooms. The findings of this study highlighted the importance of linguistic factors related to East Asian students' involvement in class. The author stated that although previous research indicated that cultural factors were associated with speech behaviors, this study demonstrated that linguistic factors were more influential as far as East Asian students' oral participation in U.S. university classrooms. This research had pragmatic implications. Based on the findings of this study, Lee recommended that cross-cultural understanding about varying classroom 
expectations and behaviors should be linked with enhanced strategies to increase opportunities for East Asian students to participate in class activities. Instructors should help minimize embarrassment of international students when they made linguistic errors and establish a supportive environment that decreased East Asian students' anxiety and fear of oral participation. American students should also help create a non-threatening and friendly classroom environment for their international peers.

The academic problems faced by international students pursuing higher education are discussed in a number of studies (e.g., Johnson 2008; Kim 2005) that have applicability to the US., as well as to other countries. For example, according to Johnson (2008), international students in New Zealand are often not able to comprehend lectures because they experience different English accents and teaching styles from lecturers who have migrated from other countries to New Zealand to take up teaching jobs. Since many international students in the U.S. are non-native English speakers, they may have difficulty in speaking and listening tasks. Classroom management strategies related to listening and speaking skills could offer international students a positive experience in the classroom (Kim, 2005). Kim discussed his research findings and offered pedagogical suggestions related to three issues in speaking and listening for international students: difficulties in note-taking and comprehension, a lack of confidence in the use of a second language, and unfamiliarity with discourse patterns and expectations in U.S. classrooms.

Galloway and Jenkins (2005), who conducted a quantitative research study on adjustment problems faced by international students, distributed the widely-used Michigan International Student Problem Inventory to international students at two universities in the United States. This inventory was concerned with a number of potential problem areas: admission and selection, orientation services, academic service, academic advising and records, socio-personal, living and dining, health services, religious services, students' activities, financial aid, placement services and the English Language. The authors discussed three insights that emerged from the study. First, learning and using the English language was one of the most important problems that international students encountered. They recommended, therefore, that universities make efforts to improve the English language proficiency of international students. The second insight was that marital status, country of origin, gender, and length of time at the university were significant determinants in at least one of the problem areas. They suggested that programs targeting specific groups of international students would serve them most effectively. The third insight concerned the disparity in problem ratings between students, faculty, and administrators, with faculty and administrators sometimes overestimating the extent of the problems faced by international students. Galloway and Jenkins suggested that administrators at the universities develop a better understanding of international students to narrow the gap between their perceptions of international students and the actual experiences of those students.

\subsection{Chinese students}

Chinese student enrollment in the United States has risen to a total of nearly 158,000 students, or nearly 22 percent of the total international student population, making China the 
leading sending country for the second year in a row. The top three sending countries-China, India and South Korea-comprised nearly half (46 percent) of the total international enrollments in U.S. higher education (Open Doors, 2011) and Chinese student enrollments increased by 23 percent in total (Open Doors, 2012). "A culturally and linguistically diverse student population challenges educators to expand their efforts toward preparing for diversity, equity, and global interconnectedness" (Suarez, 2003, p. 180). The rapid change of population requires instructors in the U.S. to be prepared to teach students who are different from themselves in racial, linguistics, and cultural aspects.

Yuan (2011) examined academic and cultural experiences of ten Chinese students at one university in the United States. Results indicated that conversational English and class discussions were the major challenges experienced by these students at school and all ten students indicated that the English language was their biggest barrier. They had limited interaction with U.S. peers and struggled to make new friends, especially U.S. friends. Chinese students tended to mingle with Chinese peers most of the time and were rarely involved in the community.

Hsieh (2007) conducted a narrative study to investigate why a Chinese female international student kept silent in her U.S.classes. This study found that the student perceived herself as a useless and deficient person in group discussions. Shedid not speak in her classes not only because of her personality but also partly because she felt disempowered and silenced by her American classmates, most of whomvalued cultural homogeneityrather than cultural diversity. U.S. society generally considers keeping silent an indication of incompetence or ignorance. Most of the international students tried to be more expressive to avoid being perceived negatively. However, because second-language learners' opportunities to speak were sometimes restricted, not all the speakers could choose opportunities to interact with their U.S. peers. This study had two suggestions for educators in higher education. First, educators should be aware of the unequal power relationships between international and U.S. students, especially in group discussions and projects since most international students do not have the same oral English proficiency as U.S. students do. College educators in the U.S. higher education system could create a power-sharing class atmosphere in which international students could feel comfortable participating in group projects and discussions. Second, they could develop a supportive atmosphere that would encourage U.S. students to develop open-minded attitudes toward diversity.

Yan and Berliner (2009) explored the stressful aspects of Chinese students' academic life in the U.S. They found that Chinese students experienced a high level of stress, caused by factors such as strong motivation to achieve academic success, ineffective interactions with U.S. professors, lack of English proficiency, and educational difference between China and the U.S.

According to Beck (2002), Chinese students were strongly influenced by the philosophy of Confucius. His philosophy has had a significant impact on Chinese individuals' viewpoints, ways of thinking, and behaviors. Tweed and Lehman (2002) summarized Confucius' philosophy of learning as "effortful learning, behavioral reform, pragmatic learning, 
acquisition of essential knowledge, and respectful learning" (p. 91). Confucius emphasized the importance of hard work and wisdom. He stated: "Wisdom, compassion, and courage are the three universally recognized moral qualities of men" (Quotations on Wisdom, 2006) and "By three methods we may learn wisdom: First, by reflection, which is noblest; Second, by imitation, which is easiest; and third by experience, which is the bitterest" (Confucius Quotes, 2006). According to Tweed and Lehman, Confucius also believed that "behavior reform is a central goal of education because virtuous behavior can ensure individual success and societal harmony" (p. 92). Confucius stressed the acquisition of essential knowledge and taught his students to respect and obey authorities. When Chinese students came to U.S. universities, they brought a Confucian-oriented perspective to their learning, while their instructors might have different philosophical orientations.

Wan (2001) conducted a case study on the learning experiences of two Chinese students at U.S. universities, including their motivations for learning, frustrations and satisfactions, strategies used to deal with language difficulties, the impact of learning on their lives, and their awareness of cultural differences in the classroom and in daily life. The study identified differences in culture, language, and social and political systems between China and the U.S. as the major source of both positive and negative experiences of these students. Wan (2001) pointed out that educators in the U.S. could help Chinese students if they became aware of their home culture, different learning styles, and frustrations in adjusting to school life.

The mother tongue of Chinese students is Chinese, not English; because of this, they experience considerable difficulty in listening, speaking, reading and writing in the U.S. college classroom. Huang (2005) reported that research showed that Chinese students in English as a Second Language classes had difficulty listening to and understanding academic lectures at U.S. universities because they were from a different educational system and cultural environment.

\subsection{A comparison between U.S. and Chinese universities}

The literature shows that instructors in U.S. and Chinese universities have unique characteristics. Nilson (1998) stated that every college and university in the U.S. was a complex organization with its own distinctive subculture, norms and values, official power structure, informal power networks, services, and support units. He listed some factors related to excellence in college-level instruction: establishing effective classroom management, protecting academic honesty, effectively making the most use of office hours, and motivating students. Simpson and Frost (1993) discussed the role of instructors in U.S. universities. In recent years, instructors have obtained resources outside of the textbook such as computers, projectors, video materials, graphics and multimedia resources. Modern instructors and students work together to meet course objectives by using various methods of instruction and learning including what Simpson and Forest (1993) referred to as instructor-centered, interactive, and individualized methods; however, instruction has become more student-centered and the individualized learning of students is increasingly stressed in the classroom. According to Gravois (2006), the U.S. Department of Education released a report about background characteristics, work activities and compensation of instructional faculty 
and staff in 2003. This report indicated that 43 percent of American faculty members worked part-time, 21 percent of full-time instructors had "non-tenure-track" positions, and the proportion of full-time faculty members who hoped to get tenured positions was increasing. Eighty-one percent of all full-time faculty members were white and 38 percent of full-time faculty were women. The report also showed that professors spent more time than ever in the classroom and that 62 percent of their time was devoted to instructional activities (Gravois, 2006).

Chinese instructors have their own unique characteristics. Liu and Qi (2006) discussed primary features about basic education in China, including large class size, more time spent by students in school, national curriculum standards, and high parental expectations. According to Romanowski (2006), Chinese education emphasizes high-stakes testing. Students spend their school years preparing for the College Entrance Exam. Today, the College Entrance Exam guarantees admission to the university and students' performance on the exam has a direct impact on their lives. Many Chinese instructors are so afraid of not adequately preparing students to take the exam, that it prevents them from focusing on important knowledge and skills; instead, they focus only on material that is likely to be covered on the exam. Because of the emphasis on the exam, Chinese instructors are more concerned with students' scores rather than other aspects, including character, emotion and thinking. According to Romanowski (2006), Chinese students could master and memorize knowledge and were excellent at preparing for exams, but lacked the ability to think critically, develop their own opinions, and engage in creative activities. The working conditions of Chinese instructors and those of U.S. instructors were different, as well. Many differences existed between most U.S. and Chinese classrooms, including class sizes, salaries, access to resources such as computers, and the physical condition of schools.

In summary, international students, particularly those from China, face a number of challenges when they pursue higher education in the U.S. because of differences in philosophical orientation, the nature of institutions of higher education, instructional goals and approaches, and student behaviors. Understanding their experiences and their perceptions is central to the purpose of the current study.

\section{Methodology}

This study involved a qualitative research design to explore Chinese doctoral students' perceptions of their university instructors in the United States. Data were collected by one research method, the individual, face-to-face interview. The researcher designed the interview questions based on the research questions and literature review and established content and face validity through consultation with individuals who were experienced in qualitative research, interview development and methodology, and issues related to international students. The researcher completed a pilot study of the interview questions by administering the interview to three Chinese doctoral students who were not participants in the data collection portion of this study. The researcher informed participants of their role in piloting the interview protocol and reminded them to respond to interview questions with the 
purpose of clarifying and improving them. They were asked not just to answer the interview questions, but, more importantly, to reflect critically on their usability, as Glesne (2010) suggests. The researcher asked for participants' feedback on the interview questions and subsequently modified the questions. The final interview protocol included several questions regarding participants' perceptions of their instructors' academic and interactive behaviors. For example, "Are your instructors in the U.S. prepared to teach when they come to class? Why do you think so? Please provide examples", and "Do you think you are respected by your instructors? Please explain with examples." Interview questions allowed the researcher to ask clarifying questions or to probe for more information, depending on the interviewees' responses.

The researcher visited the websites of several Midwestern universities to search for information related to Chinese doctoral student enrollment. Two universities that had a high proportion of Chinese doctoral students were selected for this study. An examination of the websites of the Chinese student organizations at these universities revealed that there were several publicly available lists, with contact information, of Chinese students at each university. The researcher received IRB approval of the study, emailed a recruitment letter to each student, and selected the first ten students who responded to her email and who met inclusion criteria. An attempt was made to select participants in a manner that ensured representation across university, gender, age, and field of study. Interviews were scheduled at a time and place that were mutually convenient to both researcher and participants and participants were informed that they could terminate participation at any time without harm or penalty. All interviews were audio-recorded with the permission of the interviewees. During the interview, the researcher used the interview protocol to gather answers to the questions; comments from the interviewees provided additional information. At the completion of the interviews, the researcher thanked the interviewees and explained that she would send them their interview transcripts to ensure that their perceptions had been accurately reflected. In this way, member-checking allowed the researcher to solicit comments from participants and to make modifications to the transcripts, based on their feedback. Each interview took approximately 50 minutes with an additional 50 minutes for the participants to look over their interview transcripts, for a total time commitment of about 100 minutes. All ten interviews were completed in approximately five months. Interview responses were treated with the highest confidentiality. All research procedures had been designed to protect the participants' privacy and their identity was not revealed in any way. Interview data, tapes, notes, and transcripts were securely stored for the duration of the study and all participant information was destroyed once the study was completed.

\section{Results and Discussion}

Ten Chinese doctoral students provided information about the academic and interactive behaviors of their instructors at two U.S. Midwestern universities. The participants were five male students and five female students between the ages of 25 and 40. Students majored in various fields, including Finance, Environmental Engineering, Physics Education, 
Biomedical and Biological Science, Molecular Biology, Social Work, Management Information Systems, Electrical and Engineering Systems, and Accounting. All students interviewed had pursued doctoral programs in the U.S. for at least two years.

In general, most of the participants were satisfied with the instruction they received in their university classes but had varying opinions about instructional styles in U.S. and Chinese universities. Participants described various instructional techniques used by U.S. university instructors, including group work, team work, class discussion, student-led discussion, student presentations, and lectures. Most participants believed that instructors in the U.S. were well-prepared when they came to class. They stated that they had different kinds of assignments, depending on their department, but they all agreed that they got feedback on those assignments relatively quickly.

Participants did not contact their instructors frequently but if they did have questions, they felt they could reach them easily. Most of the participants thought that instructors rarely discussed their personal issues in class. Nine of the ten participants believed that they were respected by their instructors but most of them agreed that they were not praised very often in class. They also believed that instructors took the language proficiency of Chinese students into consideration.

The researcher explored and analyzed interview data, used coding schemes to code the information, and placed the various data clusters into meaningful arrangements and themes. The answers to the research question were revealed by integration of the themes identified during data analysis. The researcher identified three themes that related to the academic behaviors of instructors and three themes that related to interactive behaviors of instructors. The following section describes and expands upon the six themes identified by the researcher.

\subsection{Themes related to academic behaviors of instructors}

The participants discussed the academic behaviors of their instructors, including pedagogical knowledge, instruction, and engagement. Three themes emerged from participant responses: engagement in instructional practice, variety of instructional methods, and adequacy of training and pedagogical knowledge.

Generally speaking, the participants were satisfied with the instruction of their instructors. The theme, engagement in instructional practice, revealed that although a few tenured professors were ill-prepared for courses, generally, instructors were well-prepared when they came to class. Well-prepared instructors gave smooth lectures, had well-organized syllabi, and regularly updated information for students. When students gave class presentations, instructors offered comments and feedback on the presentations. They made PowerPoints beforehand and updated handouts online after class. They directed students to discuss the newest and most advanced information in their fields. According to the participants, university instructors in China, like their U.S. counterparts, were also engaged in and prepared for instruction. In recent years, university instructors in China have had higher requirements as far as qualifications are concerned and increasing numbers of university instructors have obtained doctoral degrees. Participants felt that instructors in U.S. 
universities tended not to make irrelevant comments in class. Instruction was quite interactive and instructors encouraged students to think independently and express their ideas and opinions. Instructors employed technology in class, including projectors, videos and the Internet, to facilitate instruction and learning. Students could access syllabi, handouts, PowerPoints, their grades, and other personal information online. Results showed that instructors were effective and that their characteristics matched those of effective instructors as described by researchers in the field. Instructors gave participants various assignments, including research papers, weekly papers, term papers, simple homework, journals and reading reports. Apart from assignments, most participants had midterm and final exams each semester. Participants usually were given results of assignments and exams without too much delay; in China, on the other hand, because of the large number of students, university instructors usually were delayed in giving students feedback on assignments.

The participants discussed various instructional techniques used in U.S. classrooms; this reflected the second theme, variety of instructional methods. According to the participants, instructors employed various instructional techniques, including lectures, group work, team work, class discussion, student discussion and student presentations. When students gave presentations, instructors functioned as participants in the class instead of directors. Students themselves led the presentations and discussions. Some instructors required students to read journals and newspapers before class so that students could have class discussions on specific issues. Instructors would randomly ask students to give a short presentation in class, so that every student had to be well-prepared. Class discussion provided students opportunities to speak out in class and to help them express their views and hear others' ideas. Individual participants in this study had diverse learning styles. Some participants preferred lectures, from which they could obtain information while others preferred individual assignments and projects, which forced them to read reference materials and complete assignments independently. According to the participants, their instructors adopted differentiated instruction which Hall (2002) described as a flexible approach to instruction and a willingness to adjust the curriculum and present information for diverse learners in various ways. Instructors recognized differences in students' background knowledge, readiness, language, preferences in learning style, and interests and varied instruction to meet the needs of students.

The theme, adequacy of training and pedagogical knowledge, was exemplified by comments suggesting that instructors spent many years being trained and mastering their content knowledge and teaching skills before they entered the classroom. According to participants, instruction in U.S. universities was informative; instructors emphasized both practical and theoretical knowledge and provided examples related to real life.

The participants also offered their opinions on instructional styles in U.S. universities and those in China. They believed that Chinese instructors follow textbooks when they give lectures, but U.S. instructors teach according to their own notes and experiences. Instructors from both countries employed similar instructional methods, including giving lectures and using class discussion but instructors in U.S. universities had more freedom in class than those in Chinese universities. Besides, U.S. instructors had more advanced technology to 
assist with their instruction than their Chinese peers.

\subsection{Themes related to interactive behaviors of instructors}

The participants also discussed the interactive behaviors of instructors at U.S. universities, including availability, openness and respect for students. Three themes emerged from participant responses: accessibility of instructors, limited personal relationships with students, and respectful treatment of students.

The theme, accessibility of instructors, indicated that instructors were available when participants contacted them for assistance and generally set aside office hours for consultation with students. This matches Nilson's (1998) observation that factors related to college instructional excellence included effective use of office hours. On the other hand, participants stated that when students in China wanted advice from instructors, they had to ask them questions after class, look for them in the shared offices of faculty members, or call their home phone numbers.

The theme, limited personal relationships with students, suggestedthat instructors at U.S. universities were not perceived as being open to students in class regarding their personal issues. Instructors did not encourage students to discuss personal matters with them; therefore, participants were more likely to discuss academic issues with instructors. According to Lamport (1993), however, many educators in higher education believe that informal interaction between students and instructors is positively related to personal growth and academic achievement. Successful students consistently rated instructors as friends, helpers, and assistants. Informal interaction between college students and faculty affects students' academic achievement, satisfaction with college, and intellectual and personal development (Lamport, 1993). Halawah (2006) investigated the impact of student-faculty informal interpersonal relationships on students' intellectual and personal development. College professors had to be aware that posting office hours on their door and sitting in the office during those hours did not offer enough opportunities for student interaction. Professors needed to be aware of students' personality differences. The results showed that some social interaction variables, including academic integration, peer relations, social integration, informal faculty relations, faculty concern, and student commitment, could lead to intellectual and personal development of students.

All participants, with the exception of one, believed that they were respected by their instructors. The theme, respectful treatment of students, revealed that professors in the U.S. treated students with respect and honored their privacy. Instructors were open to different opinions and ideas, allowed students to express their thoughts, and were open to discussing matters on which they disagreed. Participants were praised by U.S. instructors in class or on feedback provided on assignments. Instructors in U.S. universities sometimes criticized students if they had done something wrong, but in a polite manner. In this way, they were similar to instructors in China, who also praised students, particularly when they obtained high grades on exams. 


\subsection{Comparison of instruction at U.S. and Chinese universities}

All ten participants compared instruction between universities in the U.S. and those in China and offered differing opinions of university instruction in the two countries. Some participants thought that instructional styles in the U.S. and China were different, for example, they felt that instructors in the U.S. assigned difficult homework for students that took time to complete. In China, instructors usually lectured and taught students what to do, how to do it, and what to remember while in the U.S., instructors encouraged students to think independently. Some participants found that in the U.S., professors treated instruction as a job which they loved; others preferred research and therefore, did not focus on instruction as much. In China, instruction was very important to instructors. If instructors did not teach well, they could not survive on the university campus. Other participants agreed that instructional styles in China and the U.S. were similar. At the beginning of class, both Chinese and U.S. university instructors described what they would cover in class and how they would grade students. Instructors in both countries delivered lectures, wrote notes on the blackboard, and expected students to take notes in class. Students in the U.S. and China had open discussion in class, in large groups as well as in pairs, and were free to ask questions in class.

\subsection{Male versus female perceptions}

The data gathered in this study show that male and female participants had different opinions about certain issues. Many studies have been conducted on gender differences in education. Fahy (2002) found that females were more likely to respond to messages addressed to them and were more likely to make contact with a greater number of participants in discussions. McConnell (1997) completed a study on gender participation in computer-mediated communication and found that males tended to post more and longer messages than females in mixed-gender discussions. Other studies have shown that females post more messages than males (Davidson-Shivers, Muilenburg \& Tanner 2001; Savicki, Kelly \& Ammon, 2002) and females posted more substantive comments in both threaded discussions and chats in small groups. This study revealed that some male participants do not think it is a good idea to talk about personal issues with instructors or advisors. Professors and students are not personal friends, and they only have an academic relationship. However, female participants are different. They like to talk more than male participants and also discuss many personal issues with instructors.

\subsection{Diverse opinions of participants from different majors}

Participants from different majors had differing opinions of instruction and instructors at U.S. universities. According to participants from science departments, instructors in U.S. universities gave students the solutions to assignments immediately after they had submitted their work. They stated that generally, teaching assistants graded students' work instead of instructors and that they asked for help from both instructors and teaching assistants. Students in certain science departments did not have any research papers to submit; instead, they had projects and exams to complete. The participants from the Humanities departments did not have exams; instead, they had brief assignments each week and a final paper for each course. The weekly assignment, which was usually a one-page writing assignment, comprised some 
percentage of their final grades.

\subsection{Addressing conflicts in the classroom: A comparison}

According to participants, students in the U.S. were likely to complain to Deans if their instructors did something wrong, or if they did not do what was listed in the syllabus. Chinese students, regardless of whether they are in the U.S. or China, are not used to arguing with Deans or Chairs concerning their instructors. Chinese students do not usually ask questions in class, but their U.S. peers ask instructors questions whenever something is not clear. Instructors in U.S. universities answer questions immediately and students are free to discuss those questions. Sometimes U.S. instructors even stop their lectures and follow the discussion among students since they tend not to mind student interruptions. The data gathered in this study are similar to the ideas of Hofstede (1991) and Ku et al. (2004). Hofstede (1991) stated that in the collectivist classroom, such as that found in China, students value harmony and the maintenance of "face". Students tend to avoid conflicts so that they do not hurt anyone. In contrast, students in individualist cultures, such as the U.S., frequently express opinions which are in conflict with the instructor's or with those of other students. $\mathrm{Ku}$ et al. investigated the impact of Confucian pedagogy on Chinese students. Because of the influence of Confucian pedagogy, Chinese students regard their instructors as the absolute authority and greatly respect them. Many Chinese students are not willing to share their feelings or emotions, or to express opposition to anyone, especially to their instructors.

In summary, all ten participants appeared to be quite satisfied with their instructors, particularly with regard to instruction, engagement, pedagogical knowledge, availability, openness, and respect for students. Overall, participants in this study consider instructors in U.S. universities to be effective at what they do.

\section{Limitations of the Study}

This research study had several limitations. First, the size of the sample, ten students in all, was small and was limited to two universities in the Midwest. Further, the study focused on Chinese doctoral students from mainland China, not those from Taiwan and Hong Kong, who might have had very different perceptions than their peers from China. The fact that the sample was self-selected may have introduced some bias, as well. The researcher's own status as a Chinese doctoral student may also have influenced study results. Finally, the use of interviews as a data collection method introduces potential bias, since results are based on self-report and may not be accurate.

A number of recommendations for further research are suggested as a result of this study. First, interviews could be conducted with a larger number of Chinese students at more universities, both in and outside the Midwest. In addition, surveys could be used to gather information from a larger number of students from a wider geographical area. The study could also be validated by using direct observations of instructors' teaching performance.

The study suggests several practical recommendations for students from China as well 
as faculty and administrators in the U.S. who work with international students:

\section{Recommendations for Chinese students at U.S. universities}

Many Chinese students coming from mainland China have been accepted to U.S. universities in recent years. It is not easy for them to become accustomed to U.S. culture and the U.S. university environment. Chinese students encounter many barriers, including those related to culture and language. Chinese students can spend more time with Americans and get to know their culture and traditions. Chinese students should find opportunities to improve their English language proficiency by speaking out in class to practice their oral English and setting high standards for themselves on assignments that require reading and writing ability.

\section{Instructional recommendations for U.S. university instructors}

Participants suggested that instructors could improve their teaching performance by varying the pace of lectures, preparing for courses, and providing comments on students' assignments. Changes such as these would prove beneficial to not only Chinese students, but to all students. Second, it is recommended that U.S. university instructors pay more attention to international students. They would profit from spending time talking with international students to get to know them. During office hours, instructors can discuss international students' requests and establish relationships with them. Apart from office hours, instructors can look for more chances to have conversations with international students in informal settings so as to get to know their needs, demands and difficulties, and so that they might provide more direction and help, both in and after class. Third, it would be beneficial if U.S. university instructors took international students' language and culture into consideration. It is natural for Chinese students to have difficulty in the English language when they enter U.S. universities to pursue further education, especially in the first and second years. Professors should spend more time preparing their lectures and provide more advanced information to students. Instructors, especially those from science departments, might want to read students' papers and reviews more carefully and offer more suggestions. Chinese language and culture are quite different from those in the U.S. and as such, Chinese students have difficulties in speaking, listening, writing and reading English. Instructors should offer more opportunities to students and give them more help to improve their English proficiency. Because of cultural differences, Chinese and U.S. students have different thinking patterns and distinctive ideas and opinions about academic and non-academic issues. It is suggested that instructors encourage Chinese students to express their ideas to enhance their confidence.

\section{Recommendations for U.S. university administrators}

With the increasing number of international students who come to the U.S. and pursue their education at U.S. universities, administrators might be encouraged to give more 
consideration to the multidimensional needs of all international students. International students have diverse backgrounds and speak various native languages. It is suggested that administrators provide more services to international students to help them improve their English language proficiency. They could also hold gatherings, both formal and informal, for international students to celebrate U.S. holidays so that they have a better sense of U.S. culture. Administrators are encouraged to provide specialized training for faculty who work with international students. They could also attempt to set up informal meetings between international students and faculty members, so that they can learn from and about one another.

\section{Conclusion}

This research study presented academic and interactive characteristics and behaviors of instructors at two universities in the Midwest through an investigation of the perceptions of ten Chinese doctoral students. The study contributes to the literature addressing international students' perceptions of U.S. university instructors and characteristics of U.S. university instruction.

On the whole, most of the Chinese doctoral students interviewed in the research study viewed the academic and interactive behaviors of U.S. university instructors in a positive manner. U.S. university instructors are engaged in instructional practice, have good lesson planning and preparation, and are serious about student evaluation. They respect students from other countries and tend to encourage and support foreign students. Instructors are easily accessible to students. Generally, Chinese doctoral students enrich their knowledge and broaden their horizons on U.S. university campuses.

This research study shows that Chinese doctoral students understand their disadvantages in the English language but may not always speak up in the classroom. Chinese students who attend U.S. universities or colleges need academic and personal assistance as well as consideration from their U.S. instructors, so that they can achieve academically and get used to campus life more quickly. U.S. instructors, on the other hand, could benefit from knowing more about students from other cultures, particularly Chinese students. Working together can result in a productive, mutually beneficial relationship for both Chinese students and their U.S. instructors. 


\section{References}

Austin, J. (2005). Teaching lessons from higher education. Independent School, 64(2), 101-102.

Baiocco, S. A., \& DeWaters, J. N. (1998). Successful college teaching: Problem-solving strategies of distinguished professors. Needham Heights, MA: Allyn \& Bacon.

Bain, K. (2004). What the Best College Teachers Do. Cambridge, MA: Harvard University Press.

Beck, S. (2002). Confucius and Socrates: Compare and contrast. Retrieved March 14, 2003. from http://www.san.beck.org/C\%26S-Compared.html

Burbank, M. D., Bertagnole, H., Carl, S., Longhurst, T., Powell, K., \& Dynack J. (2005). University-District Partnerships and the Recruitment of Tomorrow's Teachers: A Grassroots Effort for Preparing Quality Educators through a Teaching Academy. The Teacher Educator, 41(1), 54-69. http://dx.doi.org/10.1080/08878730509555371

Dantas, M. L. (2007). Building teacher competency to work with diverse learners in the context of international education. Teacher Education Quarterly, 34(1), 75-94.

Davidson-Shivers, G. V., Muilenburg, L., \& Tanner, E. (2001). How do students participate in synchronous and asynchronous on-line discussions? Journal of Educational Computing Research, 25, 351-366. http://dx.doi.org/10.2190/6DCH-BEN3-V7CF-QK47

Fahy, P. (2002). Epistolary and expository interaction patterns in a computer conference transcript. Journal of Distance Education, 17(1), 20-35.

Ediger, M. (1998). Determining success in university teaching. Eric Reproduction Service. College Student Journal, 32(1).

Feldman, K. A. (1976). The superior college teacher from the student's view. Research in Higher Education, 5(3), 243-288. http://dx.doi.org/10.1007/BF00991967

Galloway, F. J., \& Jenkins, J. R. (2005). The adjustment problems faced by international students in the United States: A comparison of international students and administrative perceptions at two private, religious affiliated universities. NASPA Journal, 42(2), 175-187.

Glesne, C. (2010). Becoming qualitative researchers $\left(4^{\text {th }}\right.$ ed.). New York: Longman.

Grasha, A. F. (2004). Teaching with style: The integration of teaching and learning styles in the classroom. Retrieved from http://campus.umr.edu/lead/teaching/docs/TeachingWithStyle.htm

Gravois, J. (2006). Growth inPart-Timers Slowed in Past Decade, Education Department. The Chronicle of Higher Education, 52(20), A19.

Halawah, I. (2006). The impact of student-faculty informal interpersonal relationships on intellectual and personal development. College Student Journal, 40(3), 670-678. 
Hall, T. (2002). Differentiated Instruction. Retrieved from http://www.cast.org/publications/ncac/ncac_diffinstruc.html

Hofstede, G. (1991). Cultures and organizations: Software of the mind. London: McGraw-Hill.

Huang, J. (2005). Challenges of Academic Listening in English: Reports by Chinese Students. College Student Journal, 39(3), 553-569.

Hsieh, M. (2007). Challenges for international students in higher education: one student's narrated story of invisibility and struggle. College Student Journal, 41(2), 379-391.

Johnson, M.E. (2008). An investigation into pedagogical challenges facing international tertiary-level students in New Zealand. Higher Education Research \& Development, 27(3), 231-243. http://dx.doi.org/10.1080/07294360802183796

Kelly, P., \& Moogan, Y. (2012). Culture Shock and Higher Education Performance: Implications for Teaching. Higher Education Quarterly, 66(1), 24-46. http://dx.doi.org/10.1111/j.1468-2273.2011.00505.x

Kim, S. (2005). Teaching international students. Teaching Professor, 19(4).

Ku, H., Pan, C., Tsai, M., Tao, Y., \& Cornell, R. A. (2004). The Impact of Instructional Technology Interventions on Asian Pedagogy. Educational Technology Research and Development, 52(1), 88-92. http://dx.doi.org/10.1007/BF02504776

Lamport, M. A. (1993). Student-faculty interaction and the effect on college student outcomes. Adolescence, 28(112), 971-990.

Lee, E. L. (2007). Linguistic and cultural factors in East Asian students' oral participation in U.S. university classrooms. International Education, 36(2), 27-47.

Liu, P., \& Qi, C. (2006). Examining teacher preparation in P.R. China and the U.S.: A preliminary comparative study. International Education, 35(2), 5-26.

McConnell, D. (1997). Interaction patterns of mixed sex groups in educational computer conferences. Part I-Empirical Findings. Gender and Education, 9, 345-363. http://dx.doi.org/10.1080/09540259721303

Nilson, L. B. (1998). Teaching at its best: A research-based resource for college instructors. Anker Publishing Company, Inc. Bolton, MA.

Open Doors. (2012). International student Enrollments Increased by 6 Percent. Retrieved from

http://www.iie.org/Who-We-Are/News-and-Events/Press-Center/Press-Releases/2012/1 1-13-2012-Open-Doors-International-Students

Open Doors. (2011). International student Enrollments Increased by 5 Percent in 2010/11.

Led by Strong Increase in Students from China. Retrieved from http://www.iie.org/Who-We-Are/News-and-Events/Press-Center/Press-Releases/2011/2 
011-11-14-Open-Doors-International-Students

Quotations on Wisdom. (2006). Retrieved from http://www.entplaza.com/cgi-bin/create/quotes.pl?cat=Wisdom\&main_title $=\&$ term $=6$

Romanowski, M. H. (2006). A changing nation: Issues facing Chinese teachers. Kappa Delta Pi Record, 42(2), 76-81. http://dx.doi.org/10.1080/00228958.2006.10516438

Savicki, V., Kelley, M., \& Ammon, B. (2002). Effects of training on computer-mediated communication in single or mixed gender small task groups. Computers in Human Behavior, 18, 257-269. http://dx.doi.org/10.1016/S0747-5632(01)00048-6

Simpson, R. D., \& Frost, S. H. (1993). Inside college: Undergraduate education for the future. Plenum Press: New York and London.

Suarez, D. (2003). The Development of Empathetic Dispositions through Global Experiences. Educational Horizons, 81(4), 180-182.

Tweed R. G., \& Lehman, D. R. (2002). Learning considered within a cultural context. American Psychologist, 57(2), 89-99. http://dx.doi.org/10.1037/0003-066X.57.2.89

Wan, G. (2001). The learning experience of Chinese students in American university: A cross-cultural perspective. College Student Journal, 35(1), 28-44.

Yan, K., \& Berliner, D. (2009). Chinese international students' academic stressors in the United States. College Student Journal, 43(4), 939-960.

Yuan, W. (2011). Academic and Cultural Experiences of Chinese Students at an American University: A Qualitative Study. Intercultural Communication Studies, XX(1). Retrieved from http://www.uri.edu/iaics/content/2011v20n1/11WenliYuan.pdf

Note: This paper is based on the dissertation of the first author.

\section{Copyright Disclaimer}

Copyright reserved by the author(s).

This article is an open-access article distributed under the terms and conditions of the Creative Commons Attribution license (http://creativecommons.org/licenses/by/3.0/). 